\title{
Training of Novice Researchers: A Study on the Outcomes and Benefits of Using the Problem- based Laboratory Approach as an Alternative in the Pharmacy Curriculum
}

\author{
Khor Poh-Yen* \\ Pharmacy Department, Faculty Pharmacy \& Health Sciences, Universiti Kuala Lumpur, Royal College of Medicine Perak, MALAYSIA.
}

\begin{abstract}
The objective of this research is to study the outcomes and benefits of using the ProblemBased Laboratory (PBLab) approach as an alternative to the traditionally-practised, supervisor-based research projects; in essence, the PBLab approach aims at finding out if the new approach can enhance or improve students' research experiences, capabilities and leadership qualities when they conduct a research-oriented project in a group. A group of five students in the second year Diploma in Pharmacy programme was involved in the study and key data on the students' performances, perceptions and satisfaction on the PBLab approach were collected by way of participant presentation, report writing, peer assessment, logbook evaluation and analysis of comments about the facilitator for final evaluation. The results of the research done are highly motivating and impressive; through the research, it was noted that the students responded favourably in all their feedback at the end of the project evaluation. In other words, student perception on the completion of the PBLab-based research project, peer learning and supervisor support was found to be positive and encouraging. It can firmly be said that the PBLab approach has a great potential to effectively guide a student's research projects, especially if he is a novice researcher.
\end{abstract}

Key words: Problem-based laboratory, Research, Curriculum, Pharmacy, Facilitator.

\section{INTRODUCTION}

Carrying out a research project is a compulsory component in an undergraduate curriculum ${ }^{1}$; carrying out a research project aims at developing and enhancing the students' critical thinking, independent learning and problem solving skills in addition to laying a strong foundation for conducting further research at the postgraduate level. Two previous reviews done so far show that a novice researcher encounters a number of problems/difficulties in terms of time management, stress management and inadequate supervision when carrying out a research project. ${ }^{2,3}$ These difficulties, in turn, affect his growth and interest on doing researches in the long term. In the second year of the programme in the current Diploma in
Pharmacy curriculum, students are required to register for a research project, through which they will get their first researchoriented challenge in a group-based project. Students are allowed to form a group of 4-5 students and select a research area which is relevant to their pharmaceutical science and health care specialization, and they subsequently get involved in an activity under the supervision of an academic facilitator.

The twin learning outcomes of this sort of group-based research project are, one, to enable students to apply techniques and skills they had learnt in the core module and two, to develop key transferable skills in problem solving, self-directed learning, team work, lifelong learning as well as leadership
Submission Date: 11-01-2017; Revision Date: 14-03-2017; Accepted Date: 18-03-2017

DOI: 10.5530/ijper.51.3.61 Correspondence: Khor Poh-Yen*, 3, Jalan Greentown, 30450, Ipoh, Perak, MALAYSIA. Phone: (605) 2432635 Fax: (605) 2432636 E-mail: pykhor@unik.edu.my 
skills. For instance, students, who choose a chemistryrelated health care research area, will conduct a research project in order for them to apply the concepts and laboratory techniques covered in their core chemistry module, such as titration analysis and/or chromatographic and spectroscopy method as an experimental procedure to complete their research project. Studies done in the past show that students were not given any choice to conduct a laboratory-based project. This happened due to the following factors on the students' part: A lack of idea on the area of research topic; lack of confidence in a laboratory work; and finally a lack of support from supervisors and group members., ${ }^{2,3}$ Literature review done on the integrated problem-based learning approaches used in the laboratory activities, however, showed promising outcomes; ${ }^{4,5}$ students were found to be better prepared for their individual research projects as a result of participating in problem-based miniprojects. ${ }^{6}$ Novice researchers were reported to have had an increased motivation and confidence in their lab skills and the collective research activities of the participants. ${ }^{7,8}$ Due to the fact that Problem-Based Laboratory approach has successfully improved the learning outcomes in a laboratory-based activity, this researcher was keen to find out the outcomes and benefits of applying similar PBLab principles in a specific laboratory-based research project, as an alternative approach to supervising Diploma in Pharmacy students' research projects. In this approach, this supervisory process was guided by modified problem-based laboratory processes. Multiple assessment methods were used at the end of the semester to obtain feedback from students on the outcome or effectiveness of this approach.

\section{Problem-Based Laboratory (PBLab)}

Problem-Based Laboratory (PBLab) approach was first employed by a group of researchers from University Technology Malaysia in the Bachelor of Engineering programme. ' The PBLab approach is acknowledged to be an effective teaching and learning method that can be used to promote meaningful learning and problem solving skills specifically in laboratory-related tasks. The learning process in the PBLab is actually triggered by an ill-structured, realistic problem, and hence, some studies refer to the problem as 'trigger."

Through this approach, students in this research interacted and worked collaboratively with their peers to make decisions based on facts. They went further for a deeper understanding of the matter when they tried to resolve the problem by way of conducting laboratory tests. Facilitators in the PBLab approach play a key role in probing the students' prior knowledge by way of encouraging specific kinds of cognitive activities rather than merely transmitting their expert knowledge to the students. They scaffold the students' learning by way of repeatedly asking questions and clarifications on the application of concepts, knowledge and implementation of the experiment. ${ }^{11}$

A variety of assessment methods and tools such as group presentation, logbook, peer assessment were used to monitor and assess students' achievements and participation at the end of the PBLab session. Peer assessment method was recommended to modify group marks obtained based on all the individual activities; hence, all the on-going activities were compiled in a portfolio file for monitoring and evaluation purposes., ${ }^{9} 12$

\section{Conceptual Framework of PBLab}

In this study, the researcher constructed the PBLab framework based on the literature review done (Figure 1). The assumption made is that an ill-structured problem or trigger with an underlying controversial issue could stimulate students' higher order cognitive thinking skills (that is, critical thinking and problem solving skills). The facilitator's roles here are to scaffold the students' thinking process, collaborate in peer discussion, contribute in team work development and provide leadership for independent learning skills. Due to the nature of the PBLab problem, which requires a student to conduct an experiment, hands-on skills such as measuring and observations will be introduced.

\section{DATA COLLECTION}

\section{Participants}

The population in this study was a group of Diploma in Pharmacy students from a private medical college located in the northern region of Perak, Malaysia. The selection criteria to be included were as follows: The students must have

1. undergone physical chemistry, organic chemistry, analytical chemistry and instrumental analysis courses offered by the pharmacy programme;

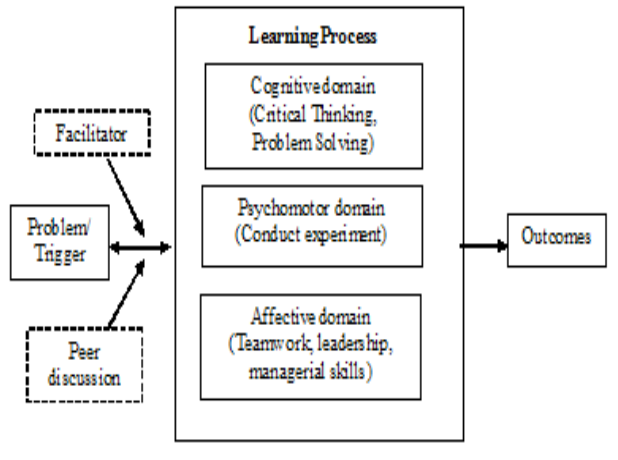

Figure 1: Conceptual Framework of PBLab. 
2. passed the research methodology module; and

3. selected a chemistry laboratory-based research as their research area.

Due to the small size of the class $(n=35)$, only one group $(n=5)$ fulfilled all the inclusion criteria and hence was allowed to participate in this study. The remaining students $(n=30)$ conducted a research project that followed the traditional research group practice. The duration of the research study followed the time frame given in the curriculum: 14 academic semester weeks. Students were informed beforehand of the consent given by their facilitator and hence voluntary participation was ensured. ${ }^{13}$

\section{Research Supervisor as the Facilitator}

Studies done in the past had shown that the facilitator should be a subject matter or content expert. ${ }^{10}$ In this study, the supervisor as the facilitator is an academic staff who is also very experienced in the research discipline. This is to avoid the difficulty later encountered by the students due to the expected lack of knowledge regarding the content of the research among students. ${ }^{3}$ In addition, the facilitator is also responsible for guiding the students through the process of sharing information, discussions, brainstorming and helping them to arrive at a group consensus.

\section{Trigger development}

Unlike in a traditional research project, students in this study were guided to formulate a problem statement on their own so that unnecessary stress and worries can be avoided. ${ }^{3,14}$ In this study, the facilitator developed an unstructured problem / trigger to stimulate the students' interest in resolving the problem scenario. ${ }^{14}$ In the very beginning of the study, the facilitator had asked students to clarify or describe a topic of their interest. With the ideas having been forwarded, the facilitator developed a problem/trigger which was related to the students' expressed interest. The trigger was later verified based on the attributes listed by Busto, Knight, Janecek, Isaac \& Parker (1994). The problem component and course component mapping were also done to ensure all the learning outcomes were covered. ${ }^{5}$ (Table 1)

\section{Time schedule/Gant chart}

The overall time schedule planned was guided by PBLab schedule. ${ }^{9,15}$ It was done as a result of discussion held with the team in the first meeting (Table 2). The time required for each stage was the average active time and student preparation time required. Since all the students were simultaneously involved in other courses as well, this research project was independent in nature. So, the students had to adjust the time schedule during the project to complete the research project within the stipulated time frame. This capability was evaluated as effective organizational skills, time management and group dynamics in their logbook. ${ }^{4}$

\section{Introduction Session 1}

In the first session, students were asked to select a chairperson and a scriber. A chairperson is responsible for agreeing to the group process, introducing the case to the group, inviting participation and ensuring that all the members contribute. ${ }^{10} \mathrm{~A}$ scriber will write down all the related ideas discussed on the white-board for a better understanding and for overseeing the timekeeping. ${ }^{10}$ The chairperson and scriber positions were rotated among the group members on a per-task basis. Unlike in the traditional research group practice, the group leader was usually selected on a rotational basis to avoid creating dominant and passive group member problems. Through this process, student leadership and teamwork skills will be efficiently developed. In the introduction session, participants were also briefed on the rubric rating scales which would be developed during the PBLab process to deliver the facilitator's expectations. ${ }^{12}$

\section{Clarification of terms}

When the facilitator showed the statement of the problem for the first time, participants were given sufficient time to define the problem using questioning prompts such as "What do you know? What are you unsure of?" and "What do you need to find out?" The role of the chairman was to ensure that all the members had agreed to the meaning of the various words and terms used and on the situation described in the problem. Students were also provided with resources such as white-boards and marker pens to write down the important points of discussion on the white-board.

\section{Facts and ideas}

After the chairman was all certain that the group had fully understood the difficult terms and the context of them appearing in the problem or trigger, he read out the trigger aloud and clearly. ${ }^{10}$ The purpose this was done was for the group to better comprehend the problem by way of visualizing the facts and ideas in the trigger. ${ }^{10}$ The scriber then wrote down all the related ideas on the white-board again for a better understanding. The facilitator then encouraged the students to come up with the initial hypotheses for the problem. He also helped them to plan what they would do for the rest of the day. 
Brainstorming (generation of hypotheses) in relation to the learning outcomes

This stage would help in activating the students' prior knowledge to understand the phenomenon and promote reasoning skills for generating hypotheses. ${ }^{10}$ It involved active discussion and exchange of knowledge and information session lead by the chairperson who is also actively assisted by the scriber to record down all the generated hypotheses. The role of the facilitator here was to ensure that the students achieved the required outcomes.

\section{Identifying resources and tools}

The facilitator got all the students involved in the designing of the experiment by way of researching appropriate techniques and procedure-based methodology as reported

\begin{tabular}{|c|c|c|c|c|}
\hline \multirow[b]{2}{*}{$\begin{array}{l}\text { Component of chemistry module } \\
\text { learning outcome }\end{array}$} & \multicolumn{4}{|c|}{ Problem Component } \\
\hline & $\begin{array}{l}\text { Potassium } \\
\text { Nitrate }\end{array}$ & $\begin{array}{l}\text { Sulfanilamide } \\
\text { solution }\end{array}$ & $\begin{array}{l}\text { N-(1-naphthyl) } \\
\text { NEDA* }^{*}\end{array}$ & $\begin{array}{c}\text { Food sample } \\
\text { (processed meat) }\end{array}$ \\
\hline \multicolumn{5}{|c|}{ Lab Techniques } \\
\hline Preparing solution & 1 & 1 & 1 & \\
\hline Dilution & 1 & & & \\
\hline Standardization & I & & & \\
\hline Calibration & 1 & & & \\
\hline Centrifugation & & & & 1 \\
\hline \multicolumn{5}{|c|}{ Instrumentation and Analytical Methods } \\
\hline Extraction & & & & 1 \\
\hline UV-Vis spectrophotometry & I & & & 1 \\
\hline
\end{tabular}

Remarks

* N-(1-naphthyl)NEDA: N-(1-Naphthyl) ethylenediamine

\begin{tabular}{|c|c|c|}
\hline $\mathbf{W}^{*}$ & In-Laboratory Session & Out-Lab Session \\
\hline W1 & $\begin{array}{l}\text { - formation of group, appointment of chairperson and } \\
\text { scriber } \\
\text { - } \quad \text { Understanding the trigger with guide from facilitator } \\
\text { - Clarification of terms }\end{array}$ & $\begin{array}{l}\text { - } \quad \text { Get more resources to help understand the trigger } \\
\text { - } \quad \text { Record all activities in the logbook } \\
\text { Schedule for the next discussion }\end{array}$ \\
\hline W2 & $\begin{array}{l}\text { - } \quad \text { Generate facts and ideas } \\
\text { - Identifying resources and tools } \\
\text { Identify what you know and what you need to know to } \\
\text { solve the problem }\end{array}$ & $\begin{array}{l}\text { - } \quad \text { Record all activities in the logbook } \\
\text { - } \quad \text { Schedule for the next discussion }\end{array}$ \\
\hline W3 & $\begin{array}{l}\text { - } \quad \text { Present solution to the facilitator } \\
\text { - } \quad \text { Facilitator comments on solution }\end{array}$ & $\begin{array}{l}\text { - Team verifies availability of equipment and tools to } \\
\text { conduct experiment }\end{array}$ \\
\hline W4 & $\begin{array}{l}\text { - Team begins to design the experiment } \\
\text { - } \quad \text { Team confirms the experiment layout }\end{array}$ & $\begin{array}{l}\text { - Team verifies availability of equipment and tools to } \\
\text { conduct experiment }\end{array}$ \\
\hline W5 & - $\quad$ Pre-laboratory session & Team verify the pre-laboratory procedure \\
\hline W6 & $\begin{array}{l}\text { - } \quad \text { Team begins to conduct actual experiment } \\
\text { - } \quad \text { Team records results from experiment work }\end{array}$ & $\begin{array}{l}\text { - Team analyses results using SPSS } \\
\text { Team discusses and decides on any repeating } \\
\text { experiment work }\end{array}$ \\
\hline $\begin{array}{l}W \\
7-8\end{array}$ & $\begin{array}{l}\text { - Team presents results to the facilitator } \\
\text { - Facilitator checks and comments on the result }\end{array}$ & $\begin{array}{l}\text { - Team prepares slides for presentation of completed } \\
\text { work } \\
\text { - } \quad \text { Team starts preparing the field report }\end{array}$ \\
\hline $\begin{array}{c}W \\
9-13\end{array}$ & $\begin{array}{l}\text { - Facilitator guides on report improvement, slides } \\
\text { presentation }\end{array}$ & $\begin{array}{l}\text { - } \quad \text { Team amends the report } \\
\text { - } \quad \text { Submit the finalized report to the facilitator }\end{array}$ \\
\hline W14 & - $\quad$ Final presentation & $\begin{array}{l}\text { - Team submits the logbook, peer evaluation forms to } \\
\text { the facilitator }\end{array}$ \\
\hline
\end{tabular}

Remarks:

W: Week

The facilitator ensures that the chairperson and scriber are changed according to the task as agreed to by team 
in the literature review, journals and other resources. Besides this, the students also had to survey the availability of the equipment, instrument, reagents, and lab scheduling to ensure that the experimental design was feasible and applicable. The students were directed to consult the laboratory technician to ensure the availability of stock and schedule for using the instrument for analysis. Since the reagent was not available in the laboratory, students were advised and facilitated with preparing a budget for purchasing chemicals or searching for other chemicals as replacement.

\section{Presenting solution to the facilitator for her comments}

The group then presented the experimental methods, equipment to be used, reagents, chemicals and procedure in preparing samples from the literature review to the facilitator. They highlighted the possibility of modifying the experimental method to suit their current research needs. At this juncture, laboratory safety rules and regulations in handling chemicals, utilizing the instruments and laboratory were also discussed. The facilitator finally commented on the solution presented by the students and the team began to design the experiment.

\section{Team confirms the experiment layout}

The students were monitored and facilitated to conduct a pre-lab activity which served as a pilot test. The students' initial answers and queries on the problems were discussed among peers in the presence of the facilitator and the laboratory technician to get further clarifications, contextual help and to identify pitfalls and blind alleys before proceeding to the actual laboratory work. ${ }^{14}$ A Pre-lab activity was also undertaken to convince students that the experiment was worth doing and that the results would be important and informative. ${ }^{16}$ This would allow the students to have some form of feelings and authority of ownership to justify the time spent on the research.

\section{Information literacy skill}

Information literacy skills were integrated along with the PBLab process. It was very important to ensure that students were able to seek outside information to assist in their problem solving process and to understand the nature and extent of the problem posed. Literacy sessions were guided by the discussion among peers and the facilitator on how to evaluate resources so that students could more readily identify criteria and signs of credibility when selecting and using data. ${ }^{17}$ Although such knowledge and skills had been taught in the research methodology subject taken before, facilitated and guided practice on literacy skills was still given again to avoid utilizing the hugely misleading data from the internet. ${ }^{3}$

\section{DATA COLLECTION}

\section{Instruments}

In this study, students were assessed by way of using the rubrics / instruments which have been created and used in the faculty for research projects for more than five years. ${ }^{18}$ More than one rubric was used with the target of assessing the process and product of this approach, ${ }^{12}$ with the process assessment emphasis on the attainment of transferable skills such as teamwork and time management. In turn, the product assessment process was targeted at developing the cognitive ability such as understanding and critical thinking skills (Table 3).

\section{Group Presentation}

The research group was allowed fifteen minutes to present its chosen topic and ten minutes to answer questions from both fellow students and the external evaluator. The evaluation of the presentation was done by instructors as well as an external evaluator. Marks on the presentation were then averaged by using presentation rubric to ensure that the marks given truly reflected the students' real ability in terms of the expected knowledge and skills acquired as outlined in the PBLab course outcomes. ${ }^{15}$ The scope of presentation was evaluated on a 5-point Likert Scale, with one indicating a poor presentation and five indicating an excellent presentation. ${ }^{19}$

\section{Peer Evaluation}

In addition to the group evaluation of the presentation, each participant was also given a written evaluation on his as well as the other peers' performances in his group. This evaluation was based on the individual contribution to the oral and written work as well as the cooperation shown towards preparing the group presentation and final written report. Peer-evaluation provided a better method of appraisal measurement. In most cases, students were able to identify the disruptive and non-participating students and awarded marks accordingly. ${ }^{19}$ This was also done to ensure that students were typically awarded with an individual grade even though the assessment was conducted on a group basis. ${ }^{12}$

\section{Logbook}

The logbook-evaluation approach was used to evaluate participant performance in the group, along with the discussion and facilitation processes. It was used as a monitoring process to avoid the group members who, not only did not prepare for the meeting, but also let others do the work in the group, which might lead to reduction in or lessen the involvement of those students who were highly motivated initially. ${ }^{11}$ In every session of the discussions held, the scriber wrote down the 
action plan for the next session. In the following meeting, the facilitator assessed the students' ability to follow through the schedule or Gantt chart. This step was taken to ensure that the students managed to complete the research project in the given time frame without jeopardizing their academic calendar and studies.

\section{Evaluation of Report}

The written-report-evaluation approach, as preferred in the dissertation format, was used in this study. The emphasis was not only on the conclusion that the students had to draw from their results and how it was related to the original problem they were given, but also on the preparation made to report it in a concise, professional and informative manner. The evaluation of the reports was done by the facilitator/supervisor herself so that the problem of inconsistency on the assessment due to misconceptions of the differing facilitator perceptions would not occur. ${ }^{15}$

\section{Feedback from the students}

As part of the evaluation process, students were required to provide the relevant feedback on the quality of the supervision provided by the facilitator and also on their overall perception of their research experiences by way of answering the following open-ended questions:
1. How did your supervisor function in facilitating you in your research project

2. (Helpful? Important? Guided?);

3. How do you think the experience you have gained from your research project can help you in your future research / studies?;and

4. How would you describe your experience in completing the research project?

\section{RESULTS AND DISCUSSION}

\section{Group Presentation, Peer Evaluation, logbook and report evaluation}

The summary of result (Table 4) describes the quality of implementation of the PBLab approach in the supervision of a student-lead research project.

It was noted that, from the students' performance in research write-up, they had achieved and shown versatility in conducting the research project by scoring 28 out of 35 marks. This in turn shows they possess problem solving and scientific writing skills.

From the peer evaluation feedback result (Table 4), it was noted that the peer evaluation score varied from one student to another, indicating that students gave a real feedback according to their peer's contribution in the research process. This researcher believes that the

\begin{tabular}{|c|c|c|c|c|c|c|c|c|c|c|c|}
\hline \multicolumn{1}{|c|}{ Table 3: Assessment, Mode and Dominant Learning Outcome } \\
\hline No & Assessment & Mode & \multirow{2}{*}{$\%$} & \multicolumn{7}{|c|}{ Dominant Learning Outcome } \\
\cline { 5 - 13 } & & & & K & P & S & E & T & C & M & En \\
\hline 1 & Research report & Team & 35 & $/$ & $/$ & $/$ & $/$ & & $/$ & & n.a \\
\hline 2 & Presentation & Team & 30 & $/$ & & $/$ & $/$ & & $/$ & & n.a \\
\hline 3 & Peer evaluation & Individual & 5 & $/$ & $/$ & $/$ & $/$ & $/$ & $/$ & $/$ & n.a \\
\hline 4 & Logbook & Individual & 30 & $/$ & $/$ & $/$ & & $/$ & $/$ & $/$ & n.a \\
\hline
\end{tabular}

Remarks:

K: Knowledge; P: Practical; S: Social; E: Ethics; T: Teamwork \& Communication; C: Critical Thinking; M: Managerial skills; En: Entrepreneurship;

n.a: Not Applicable

\begin{tabular}{|c|c|c|c|c|}
\hline \multicolumn{5}{|c|}{ Table 4: Result from Report Assessment, Group Presentation, } \\
Peer Evaluation and Logbook \\
\hline Student \# & $\begin{array}{c}\text { Report } \\
\mathbf{( 3 5 \% )}\end{array}$ & $\begin{array}{c}\text { Group } \\
\text { Presentation } \\
\mathbf{( 3 0 \% )}\end{array}$ & $\begin{array}{c}\text { Peer } \\
\text { Evaluation } \\
\mathbf{( 5 \% )}\end{array}$ & $\begin{array}{c}\text { Logbook } \\
\mathbf{( 3 0 \% )}\end{array}$ \\
\hline 1 & 28.0 & 19.1 & 15 & 24 \\
\hline 2 & 28.0 & 19.1 & 16 & 26 \\
\hline 3 & 28.0 & 19.1 & 15 & 23 \\
\hline 4 & 28.0 & 19.1 & 14 & 25 \\
\hline 5 & 28.0 & 19.1 & 14 & 25 \\
\hline Mean \pm SD & $28.0 \pm 0$ & $19.1 \pm 0$ & $15 \pm 0.54$ & $25 \pm 1.1$ \\
\hline
\end{tabular}


collaborative process involved throughout the project had stimulated and motivated students towards experiencing a meaningful learning. ${ }^{11}$

\section{Feedback from students}

The analysis of students' feedback and comments about the facilitator revealed that students viewed the role of the facilitator as very helpful and they thought that it was very important for the facilitator's presence when conducting a research. Samples of comments are as follows:

"...helped the whole team (by way of giving ideas and opinion and suggestions)".

"...I love the way she had lead us. She helped us from the beginning till the end; she had also demonstrated how she believed in all of us".

"...her comments and guidelines really helped us to improve this research".

"....our facilitator was a very observant person; she is also someone whom we could refer to as much as we wanted, since the drafts of the report would only be sent to (the facilitator) before the final submission. This helped us to improve our research project to have a better quality and to make the project more organized". “...our supervisor (facilitator) really did a good job in helping us to do the research especially in the writing of the report. One of her roles was to correct and give us some ideas to help us produce a high quality research project".

The above is in line with the findings from a previous study which mentioned that the facilitator is more a determining factor than does the role of the trigger chosen in the overall achievement of PBL objectives. ${ }^{20}$

This researcher had also observed that after introducing this approach, students had shown some interest on the idea and importance of doing a research and as a result, were well-prepared for carrying out any sort of research in future. Samples of comments are as follows:

"I have learnt how to prepare a good report and how we must focus on every detail as even a simple mistake can ruin our research".

"I have learnt how to manage a research proposal and report it correctly, not to mention how to obtain a good title for our research project which suits our methodology. I have also learnt why some of the methods are accepted or rejected based on certain criteria".

“...Doing a lab research will help me in my future studies; for example, when doing our pilot test based on the current research, we can successfully learn how to figure out some errors and learn from it".
This is consistent with the previous findings which showed that PBLab benefits the students in real terms especially in improving their technical and generic skills for their future studies. ${ }^{15}$

Looking at the following comments, it can be noted that students perceive the idea of doing a research positively and as encouraging as they had gained valuable experience and knowledge from the research activities:

".....improved my skills in team work and gained valuable knowledge".

"... happy and excited simply because it is a great achievement for all of us!"

"...When all of us were doing the research, I could feel that everyone wanted a good result. We wish to thank to our leader as she did really play her role and she helped us to do our part better. I feel happy because we worked as a team and the result has turned out to be excellent!" "...the feeling of enthusiasm is in the air. We are so excited to know the outcomes of our research project irrespective of whether we have achieved our objectives or not".

"...As for me, a good teamwork is needed as it is one of the vital requirements to achieve a better result for the project. I am really glad to have had such supportive team members by my side throughout this project. The feeling I had when our project was graded as one of the best research projects is indescribable as it really shows that our hard work has finally paid off. This would be an encouragement for me to do more research projects in future".

\section{Limitation of Study}

This study was based only on a relatively small sample size and as a result, it would not necessarily be congruent with or representative of the overall population. In future, studies should involve a much bigger population with the involvement of more research groups. This will, in return, encourage the involvement of more facilitators so that a better briefing, training and monitoring process can be used to ensure consistency and reliability of the PBLab supervision, assessment and evaluation procedures or methodology applied.

\section{CONCLUSION}

Due to the current growing demand for pharmacy education, Diploma graduates are expected to be very competent in terms of knowledge, personal and independent learning skills. Developing qualitative research skills and cultivating interest in research along with the accumulated positive research experiences are expected to add qualitative value to the students not only in the 
real workplace but also when pursuing graduate studies. Positive outcomes from this research study shows PBLab holds, in fact, a great potential for facilitating and guiding novice researchers towards the completion of their research projects more effectively, qualitatively and independently.

\section{ACKNOWLEDGEMENT}

Thanks to the respondent for their voluntary participation in this study. A heartfelt appreciation is also due to Prof. Dr. Mohd Syafiq bin Abdullah who still remains as a source of strength and inspiration to this researcher.

\section{CONFLICT OF INTEREST}

Nil.

\section{ABBREVIATION}

PBLab: Problem-Based Laboratory

\section{REFERENCES}

1. Sreedharan J. Introduction of a research component in the undergraduate medical curriculum - Review of a trend. Nepal Journal of Epidemiology.2012;2(3):200-4. https://doi.org/10.3126/nje.v2i3.6901.

2. Bocar AC. Difficulties Encountered By the Student - Researchers and the Effects on Their Research Output. 2013:61-67.

3. Ellis TJ, Levy Y. Towards a guide for novice researchers on research methodology: Review and proposed methods. Issues in Informing Science and Information Technology. 2009;6(1):323-37.

4. Saloranta T, Lönnqvist J-E, Eklund PC. Transforming Undergraduate Students into Junior Researchers: Oxidation-Reduction Sequence as a Problem-Based Case Study. J Chem Educ. 2016; 93(5):841-6. https://doi. org/10.1021/acs.jchemed.5b00495.

5. Ram P. Problem-Based Learning in Undergraduate Instruction. A Sophomore Chemistry Laboratory. J Chem Educ. 1999;76(8):1122. https://doi.org/ 10.1021/ed076p1122.
6. McDonnell C, O'Connor C, Seery MK. Developing practical chemistry skills by means of student-driven problem based learning mini-projects. Chem Educ Res Pract. 2007;8(2):130-9. https://doi.org/10.1039/B6RP90026G.

7. Kerr MA, Yan F. Incorporating Course-Based Undergraduate Research Experiences into Analytical Chemistry Laboratory Curricula. J Chem Educ. 2016;93(4):658-62. https://doi.org/10.1021/acs.jchemed.5b00547.

8. Davis TH, Wagner GS, Gleim G, etal. Problem-based learning of research skills. J Electrocardiol. 2006;39(1):120-8. https://doi.org/10.1016/j.jelectrocard. 2005.06.107; PMid:16387065.

9. Azli N, Tan C, Ramli N. Implementation Model of a Problem-Based Laboratory (PBlab) Established for a Bachelor Of Engineering (Electrical) Program at Universiti Teknologi Malaysia. RCEE \& RHEd. 2010;1-5.

10. Ansari MT, Abd Rahman S, Badgujar VB, Sami F, Abdullah MS. Problem Based Learning (PBL): A Novel and Effective Tool of Teaching and Learning. Indian J Pharm Educ Res. 2015;49(4):258-65. https://doi.org/10.5530/ ijper.49.4.3.

11. Dolmans DHJM, De Grave W, Wolfhagen IHAP, Van Der Vleuten CPM. Problem-based learning: Future challenges for educational practice and research. Med Educ. 2005;39(7):732-41. https://doi.org/10.1111/j.13652929.2005.02205.x; PMid:15960794

12. Alias M, Sulaiman Y. Problem Based Learning Model : A Collection From the Literature. Asian Soc Sci. 2010;6(8):148-56.

13. Creswell JW. Educational Research: Planning, Conducting, and Evaluating Quantitative and Qualitative Research. Boston: Pearson Education;2012.

14. Kelly OC, Finlayson OE. Providing solutions through problem-based learning for the undergraduate 1st year chemistry laboratory. Chem Educ Res Pract. 2007;8(3):347-61. https://doi.org/10.1039/B7RP90009K.

15. Bahri NAS, Azli NA, Samah NA. Problem-Based Learning Laboratory (PBLab): Facilitators' Perspective on Rubric Assessment. Procedia - Soc Behav Sci. 2012;56:88-95. https://doi.org/10.1016/j.sbspro.2012.09.635.

16. Johnstone a H. Chemistry Teaching - Science or Alchemy ? 1996 Brasted Lecture. J Chem Educ. 1997;74(3):262-68. https://doi.org/10.1021/ ed074p262.

17. Shultz G V., Li Y. Student Development of Information Literacy Skills during Problem-Based Organic Chemistry Laboratory Experiments. J Chem Educ. 2016;93(3):413-22. https://doi.org/10.1021/acs.jchemed.5b00523.

18. Universiti Kuala Lumpur. Final Year Project. Manual for Degree Programmes.

19. Busto U, Knight K, Janecek E, Isaac P, Parker K. a Problem-Based Learning Course for Pharmacy Students on Alcohol and Psychoactive SubstanceAbuse Disorders. Am J Pharm Educ. 1994;58(1):55-60.

20. Tarhan L, Ayyildiz Y. The Views of Undergraduates about Problem-based Learning Applications in a Biochemistry Course. J Biol Educ. 2015;49(2):116-26. https://doi.org/10.1080/00219266.2014.888364.

\section{SUMMARY}

This is the first study reported the outcomes and benefits of using the PBLab approach as an alternative to the traditionally-practised, supervised-based research projects.

1. Student perception on the completion of the PBLab-based research project, peer learning and supervisor support was found to be positive and encouraging.

2. PBLab approach has a great potential for facilitating and guiding novice researchers towards the completion of their research project more effectively.

\section{Supplementary material}

\section{Trigger}

Nitrite in the form of sodium or potassium is a chemical that is most commonly used in the preservation of processed meat. However, nitrite can react with the secondary amines in the meat to form Nitrosamine that can accelerate the formation and growth of cancer cells throughout the body. Permissible limits for residual Nitrite in any processed meat should be in the range of 40-100 ppm. Investigations if food preparation or cooking methods can change the residual nitrite, however, are still inconclusive. 


\section{Clarification of terms}

Facilitator: What do you know about ....?

- Nitrite

- Residual Nitrite

- Preservatives

- Processed meat

- Nitrosamine

- Secondary amine

- Permissible limit

\section{Brainstorming and idea generation}

Facilitator: How does nitrite preserve the processed meat?

Possible answer:

- Nitrite is first reduced to Nitric Oxide in the meat by naturally-occurring bacteria; the newly-formed Nitric Oxide then reacts with myoglobin to produce and stabilize red meat colour through an extended shelf life of meat

- Nitrite is used to inhibit the growth of Clostridium botulinum, the most widely recognized food-spoiling and food-poisoning bacteria

- Nitrite is able to inhibit and prevent division of the vegetative cells emerging from surviving spores of the Clostridium botulinum, and hence, delays the development of oxidative rancidity and this contributes to the flavour development of meat

What do you know about the health risk of residual nitrite?

Possible answer:

- Children from birth to ten years, who eat more than 12 hotdogs per month, have nine times higher risk of developing childhood leukemia, especially if the food is consumed on a regular basis during the first 2 years of life

- Children born to mothers who consumed hotdogs once or more times per week during the pregnancy have approximately doubled the risk of developing brain tumors

- The excess risk in the highest category of processed meat-eaters comprised between $20 \%$ and $50 \%$ compared with non-eaters

What is the range of residual nitrate in the processed meat?

- Limited the maximum ingoing / nitrite content to $200 \mathrm{ppm}$

- Residual nitrite in the end products is recommended not to exceed 4 ppm

\section{Experimental Method:}

\section{Chemicals}

- Sulfanilamide solution

- $\quad 0.5 \% \mathrm{~N}$-(1-naphthyl) ethylenediamine dihydrochloride (NEDA)

- Potassium Nitrite standard solution $(0.1 \mathrm{mg} / \mathrm{L}, 0.2 \mathrm{mg} / \mathrm{L}, 0.3 \mathrm{mg} / \mathrm{L}, 0.4 \mathrm{mg} / \mathrm{L}$ and $0.5 \mathrm{mg} / \mathrm{L}$ )

\section{Preparation of standard solution}

- Weigh $0.5 \mathrm{mg}$ of Potassium Nitrite and dissolve it in one liter volumetric flask with distilled water, labeled as $0.5 \mathrm{mg} / \mathrm{L}$ Potassium Nitrate

- Dilute $0.5 \mathrm{mg} / \mathrm{L}$ Potassium Nitrite to get $0.4 \mathrm{mg} / \mathrm{L}$, and followed $0.3 \mathrm{mg} / \mathrm{L}, 0.2 \mathrm{mg} / \mathrm{L}$ and $0.1 \mathrm{mg} / \mathrm{L}$ Potassium Nitrate.

\section{Food samples:}

- Three packets of sausages from one of the randomly selected brands available in the supermarkets were purchased for research. The sausages were then brought directly to the laboratory for a determination process. 


\section{Extraction:}

- Processed meat was weighed and cut into 10 grams (for use during the boiling, frying and heating methods of cooking in a microwave)

- The processed meat was boiled in $200 \mathrm{~mL}$ of distilled water (boiling method)

- Fried in $5 \mathrm{ml}$ of selected cooking oil (frying method)

- Heat in a microwave under medium (heat for five minutes) respectively

- Each of the cooked hotdog was weighed, added to $30 \mathrm{ml}$ distilled water and grinded thoroughly with a mortar and pestle.

- The supernatant obtained was poured into a test tube and centrifuged

\section{Instrumentation:}

- UV/Vis Spectrophotometer (Perkin Elmer)

\section{Calibration:}

- The absorbance rate was measured at wavelength of $543 \mathrm{~nm}$ for all standard solution on the spectrophotometer against distilled water blank.

\section{Preparation of Nitrate sample}

- One milliliter each sample supernatant prepared was transferred into a $25 \mathrm{~mL}$ beaker

- $1 \mathrm{~mL}$ of each standard solution and $1 \mathrm{~mL}$ of control sample was added into separate $25 \mathrm{~mL}$ beakers

- About $5 \mathrm{ml}$ of sulfanilamide solution was then added, mixed and allowed to stand for 20 minutes

- After 20 minutes, prepared samples were followed by $0.5 \mathrm{~mL}$ of $5 \%$ NEDA for the full development of the characteristic pinkish-red color

\section{Determining Nitrite content in food sample}

- Prepared Nitrite sample is measured at wavelength of $543 \mathrm{~nm}$

- Content of Nitrite in sample is observed from the calibration curve

\section{Statistical analysis}

- Statistical Package for Social Science (SPSS) version 21 was extensively used

- The results were expressed as mean $\pm \mathrm{SD}$.

- The One Way ANOVA method was used to analyse the means differences among the samples under different treatments.

- The significant level was set at $\mathrm{P}<0.05$

\section{About Authors}

Khor Poh Yen: Is working as a senior lecturer in Pharmacy Programme, Faculty of Pharmacy \& Health Science in Universiti Kuala Lumpur, Royal College of Medicine Perak, Malaysia. She completed her Master in Education from Open Universiti Malaysia and Master in Science (Chemistry) from University of Malaya, Malaysia.

Cite this article: Poh-Yen K. Training of Novice Researchers: A Study on the Outcomes and Benefits of Using the Problembased Laboratory Approach as an Alternative in the Pharmacy Curriculum. Indian $\mathrm{J}$ of Pharmaceutical Education and Research.2017;51(3):355-64. 